\title{
Structural Change behind GDP Growth Rates via Key Indicators: Chile 1996-2015
}

\author{
J.M. Albala-Bertrand ${ }^{1}$ \\ ${ }^{1}$ School of Economics and Finance, Queen Mary, Univ. of London, Mile End Road, London E1 4NS, UK \\ Correspondence: J.M. Albala-Bertrand, School of Economics and Finance, Queen Mary, Univ. of London, Mile End \\ Road, London E1 4NS, UK.
}

Received: June 4, 2018

Accepted: June 25, $2018 \quad$ Online Published: July 7, 2018

doi:10.5539/ibr.v11n8p38

URL: https://doi.org/10.5539/ibr.v11n8p38

\begin{abstract}
This paper deals with the change of some aggregate structural indicators in Chile over the 20-year period 1996-2015. We first produce an accounting growth decomposition to assess the changes in the contribution of capital productivity, capital intensity and labour participation to the growth rate of output per capita as well as the growth rate of labour income participation in national income. We then combine an accounting growth decomposition with a standard production function growth accounting to assess the contribution of both capital productivity and capital intensity to total factor productivity (TFP). To complement the latter, we produce optimal estimates of incremental capital productivity and incremental income elasticity to capital by means of a linear programming exercise. Our main conclusion is that capital intensity, rather than capital productivity or labour participation, has been the main growth contributor. TFP has contributed in a decreasing way from positive to negative over our sub-periods, so adding to and subtracting from GDP growth over time, with the main positive contributor to TFP growth systematically being a proportion of capital intensity.
\end{abstract}

Keywords: structural change, incremental capital productivity, growth decomposition, optimal consistency method (OCM), total factor productivity (TFP)

JEL Classification: O4, B4, E2

\section{Introduction}

There has been a good deal of macroeconomic studies about Chile's productivity and related issues. These are normally framed in standard production functions, especially the Cobb-Douglas, via growth accounting (Denison 1993, Hulten 1992), under the assumption of constant returns to scale (CRS) and often, implicitly or otherwise, assuming perfect competition with their theoretically convenient marginal conditions. CRS is often imposed in econometrics studies or directly used to calculate the elasticities via some estimation of the actual capital share in GDP from official statistics, which is unwarranted. In turn, the income elasticities of capital and labour are assumed constant over all the target period, which may be unlikely (e.g. Beltran 2017, Fuentes, Larraín \& Schmidt-Hebbel, 2006; Dipres; CNP). This means that the results necessarily carry a baggage of assumptions that may not tally with the reality of especially relative latecomers and/or countries with unstable growth, let alone those undergoing significant structural change, as has been the case of Chile. This is especially the case over 1975-1985, which includes a deep downturn over 1982-85, then a recovery at lower rates over 1985-1990, then after some policy adjustments coming from the newly reestablished democracy, high growth rates over 1990-1997, and after it a slowdown due to internal policy changes and world shocks. All this within a relative stable economic consolidation in a very open economy over the period 1996-2015, which was affected by three foreign shocks: the Mexico crisis of 1994, the Asian crisis of 1997 and the Great Recession with effect from 2008 (Ffrench-Davis, 2018, 2014).

The present paper attempts an aggregate viewpoint that is more founded on empirical patterns than theoretical assumptions and may complement alternative approaches. This is a quantitative paper that deals with structural indicators that are mostly based on definitional accounting, rather than functional, relationships. The point is to produce useful decompositions of growth rates by means of discrete first differences. And then observe compositional contributions to the actual growth rates as well as to total factor productivity (TFP), among other relevant items. The paper structure is as follows. First, we produce a definitional accounting growth decomposition via first differences to assess the changes in the contributions of capital productivity, capital 
intensity and labour participation to the growth rate of output per capita over the said period. We also produce a decomposition of the growth rate of labour-income participation in national income via the difference between the growth rates of average wages and average labour productivity. Second, we combine a definitional accounting decomposition with a standard growth accounting decomposition of a production function to assess the contribution of both capital productivity and capital intensity to the total factor productivity growth rate $\left(G_{T F P}\right)$. Then we produce aggregate estimates of the optimal productivities of incremental capital over this 20 -year period by means of a linear programming exercise to complement the above. This latter approach may reduce the difficulty of assessing idleness, as capital formation is related to optimal output directly (Albala-Bertrand 2010) ${ }^{(1)}$. From here, a value for the optimal incremental income elasticity of capital can be derived, which can give us an idea about the level and variability of the marginal elasticity of capital used in standard production functions. All our basic data comes from official Chilean sources, unless otherwise indicated $^{(2)}$.

As a general conclusion, we show that the growth contribution of capital productivity has been becoming small and/or negative, and that of labour participation positive but secondary to capital intensity. The latter has taken the bulk of supporting both GDP growth and total factor productivity. This does not necessarily mean that GDP growth has relied on the quantity rather than the quality of resources and production, as behind capital intensity are changes in human capital, organization, adaptations, technical efficiency and the like. So it has not just been physical capital, but the important changes in economic and social structure required to use it and absorb it.

\section{General Background}

The context for our results can be seen via the 3-year average values of some key variables for both 1996 and 2005.

Table 1. Basic data for beginning and end of the period (3-year moving averages)

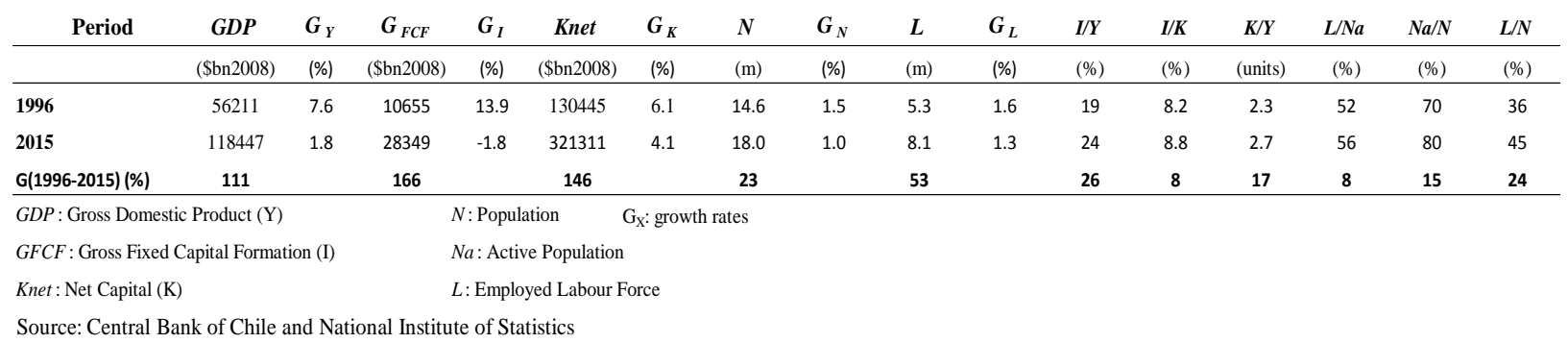

Table 1 shows, in 3-year averages, the state of some economic indicators at the beginning and end of our focus period. The growth rates of $G D P$, investment $(G F C F)$, net capital stock (Knet), population $(N)$ and secondarily employment $(L)$ significantly fell (or were negative) by 2015. In turn, the investment coefficient $(I / Y)$ significantly increased with secondary increases in the capital accumulation rate $(I / K)$, and also in the proportion of labour employed-to-active population $(L / N a)$ as well as the proportions of both active population-to-total employment $(N a / N)$ and employment-to-total population $(L / N)$. The capital-output ratio $(K / Y)$ increased, indicating that its inverse, the average productivity of capital, fell. So this shows a mixed bag, which can be attributed to a combination of international conditions, endogenous structural change and important policy reforms, especially those starting around 2015 (Ffrench-Davis 2018).

\section{Discrete Growth Decomposition Analysis}

A definition of output per capita, $Y / N$, can be decomposed as:

$$
Y / N=(Y / K)(K / L)(L / N a)(N a / N)
$$

Where $Y$ : output, $N$ : population, $K$ : net capital stock, and $L$ : Labour. That is, output per capita is equal to the product of capital productivity $(Y / K)$, capital intensity $(K / L)$ and labour participation $(L / N)$. The latter split into employed labour-to-active population and active population-to-total population. Calculating the first difference of (1), dividing by $(Y / N)_{0}$ and manipulating to transform all terms into growth rates, we get:

$$
\begin{gathered}
G_{Y / N}=G_{Y / K}+G_{K / L}+G_{L N a}+G_{N a / N}+G_{Y / K} G_{K / L}+G_{Y / K} G_{L / N a}+G_{Y / K} G_{N a / N}+G_{K / L} G_{L N a}+G_{K / L} G_{N a / N}+G_{L / N a} G_{N a / N}+ \\
G_{Y / K} G_{K / L} G_{L N a}+G_{Y / K} G_{K / L} G_{N a / N}+G_{K / L} G_{L / N a} G_{N a / N}+G_{Y / K} G_{K / L} G_{L / N a} G_{N a / N}
\end{gathered}
$$


This shows that the discrete growth rate of income per capita is equal to the addition of the growth rates of its four components plus their interactive terms. If we proportionally distribute the interactive terms into the three basic growth rates, as we do in the calculation later, we preserve the accounting identity and get:

$$
G_{Y / N}=G_{Y / K}^{\prime}+G_{K / L}^{\prime}+G_{L N a}^{\prime}+G_{N a / N}^{\prime}
$$

Where $\mathrm{G}^{\prime}$ indicates that the interactive terms have been incorporated to the growth rates, as mentioned above ${ }^{(3)}$. Notice that the addition of the first two terms on the right hand side of equation (3) is equal to the growth rate of labour productivity $G_{Y L}^{\prime}$, which we use below. Similarly, we can have a measure of the evolution of the change rate of the wage share in GDP by means of making $W / L=(W / Y)(Y / L)$, or the wage rate equal to the wage share times labour productivity (where $W$ : total real wages). Applying the same procedure as above, we end up with $G_{W / L}=G^{\prime}{ }_{W / Y}+G_{Y / L}{ }_{Y L}$ So solving for $G^{\prime}{ }_{W / Y}$, we get:

$$
G_{W / Y}^{\prime}=G_{W / L}-G^{\prime}{ }_{Y / L}
$$

That is, the growth rate (or rate of change) of the share of wages in GDP is equal to the growth rate of the average wage minus the growth rate of the average productivity of labour. Notice also that the growth rate of the share of wages in $G D P$ would correspond to the growth rate of the average labour-unit cost of the economy.

Table 2. Contributions to the Growth of Income per capita (in percentage points, pp)

\begin{tabular}{cccccc|ccc} 
Period & $\boldsymbol{G}_{\boldsymbol{Y} / \boldsymbol{K}}^{\prime}$ & $\boldsymbol{G}_{\boldsymbol{K} / \boldsymbol{L}}^{\prime}$ & $\boldsymbol{G}_{\boldsymbol{L} / \boldsymbol{N} \boldsymbol{a}}^{\prime}$ & $\boldsymbol{G}^{\prime}{ }_{\boldsymbol{N} / \boldsymbol{N}}$ & $\boldsymbol{G}_{\boldsymbol{Y} / \boldsymbol{N}}$ & $\boldsymbol{G}_{\boldsymbol{W / L}}^{\prime}$ & $\boldsymbol{G}_{\boldsymbol{Y} / \boldsymbol{L}}^{\prime}$ & $\boldsymbol{G}_{\boldsymbol{W} / \boldsymbol{Y}}^{\prime}$ \\
\hline $\mathbf{1 9 9 6 - 2 0 0 0}$ & -0.8 & 4.0 & -0.7 & 0.5 & $\mathbf{3 . 1}$ & 1.2 & 3.2 & $\mathbf{- 2 . 0}$ \\
$\mathbf{2 0 0 1 - 2 0 0 5}$ & 0.3 & 1.8 & 0.5 & 1.1 & $\mathbf{3 . 7}$ & 1.9 & 2.0 & $\mathbf{- 0 . 1}$ \\
$\mathbf{2 0 0 6 - 2 0 1 0}$ & -1.1 & 2.1 & 1.0 & 0.6 & $\mathbf{2 . 7}$ & 2.6 & 1.0 & $\mathbf{1 . 6}$ \\
$\mathbf{2 0 1 1 - 2 0 1 5}$ & -1.1 & 2.6 & 0.7 & 0.5 & $\mathbf{2 . 7}$ & 1.8 & 1.4 & $\mathbf{0 . 4}$ \\
Average 1996-2005 & -0.2 & 2.9 & 0.7 & 0.8 & $\mathbf{3 . 4}$ & 1.5 & 2.6 & $\mathbf{- 1 . 1}$ \\
Average 2006-2015 & -1.1 & 2.4 & 0.9 & 0.6 & $\mathbf{2 . 7}$ & 2.2 & 1.2 & $\mathbf{1 . 0}$ \\
Average 1996-2015 & -0.7 & 2.6 & 0.4 & 0.7 & $\mathbf{3 . 0}$ & 1.9 & 1.9 & $\mathbf{0 . 0}$ \\
\hline
\end{tabular}

Table 2 shows the growth contribution of capital productivity $\left(G^{\prime}{ }_{Y / K}\right)$, capital intensity $\left(G_{K / L}^{\prime}\right)$, employed-labour participation $\left(G^{\prime}{ }_{L N a}\right)$ and the proportion of active population-to-total population $\left(G^{\prime}{ }^{\prime}{ }^{\prime} / N\right)$ to the growth rate of income per-capita $\left(G_{Y / N}\right)$. In other words, the former four represent the contribution in terms of percentage points (pp) to the latter, so they add up to the value of the latter. As a whole, the capital productivity $(Y / K)$ contribution has been negative, except for 2001-05 where is slightly positive, becoming a negative contributor to the growth rate of GDP per capita over the whole period, which made the productivity of labour fall too (i.e. $G_{Y / K}^{\prime}+G_{K / L}^{\prime}$ ). This is consistent with the declining or constant optimal incremental capital productivity as shown in the Appendix. Capital intensity $(K / L)$, however, represents the most important contributor to the GDP per-capita growth rate, representing for the whole period around $70 \%$ of the positive contributions to such a rate. This means that it has also been contributing to compensate for the decline in capital productivity. The remaining $30 \%$ of the rate has been carried by both employed labour participation $(L / N a)$ and active population participation $(\mathrm{Na} / \mathrm{N})$. Does this mean that it is the quantity rather than the quality of resources that appear to be largely the driving force behind the growth of output? To help sort out such question, we turn to our proposed decomposition of total factor productivity in the next section. But before let us have a look at labour-income participation in total GDP, which is represented in growth rates in the last three columns of Table 2 above.

Three important observations come from such data. First, the growth rate of the average real wage of the economy (or real wage rate) has been systematically increasing over the sample period. Second, the productivity of employed labour (i.e. $G_{Y / K}^{\prime}+G_{K / L}^{\prime}$ ) has been positive all along, representing some $65 \%$ of the growth rate of GDP per capita, mostly on account of capital intensity, as shown above. And third, the previous two rates have on the whole made the growth rate of labour-income participation in GDP about even for the whole period, which is consistent with other sources that show a wage participation in value added of around $42 \%$ over this period (Banco Central, 2016). In other words, the gains in labour productivity have been proportionally passed to labour income on the whole, but not in a stable manner. The 1996-2000 period shows that this transfer falls significantly short of it, then improving but still negative over the 2001-2005 period, and then showing a positive but declining excess over the last two periods. This also mean that the average labour-unit cost (or wage cost to produce one unit of GDP), which is another way to look at the 
employed-labour income share in GDP has been about constant over the whole period. The text recommendation is that average wages should grow at the same rate as labour productivity. If income distribution was not an issue, i.e. if the Gini coefficient or any other measure shows low levels of inequality, then the result above would be of little concern, as long as it was systematic. But in the case of Chile, where inequalities are high (Casen, OECD), this result is troubling as it may show a persistence of inequality. Of course, labour productivity should grow at higher rates to secure a stable reduction in inequalities, but causation may also run the other way, i.e. higher wages may stimulate higher productivity (Taylor, 2004; Peach \& Stanley, 2009).

The analysis above accounts for the evolution of some important structural contributors to the growth of the Chilean economy up until 2015. The significant reforms that started in early 2015, which also created significant political opposition and conflict, together with a deep slip in international commodity prices (notably copper, still the main Chilean export) did upset the economy and its GDP growth rate up until the time of this writing (Ffrench-Davis, 2018). The reforms however are only likely to start consolidating and delivering their aims over the medium term.

\section{A Decomposition of Total Factor Productivity (TFP)}

If we combine an accounting decomposition of the growth rate of labour productivity (equation 5) with a standard production function growth accounting (equation 6), we can then derive a decomposition of TFP.

$$
\begin{gathered}
G_{Y / L}=G_{Y / K}^{\prime}+G_{K / L}^{\prime} \\
G_{Y / L}=G_{T F P}+\alpha G_{K / L}^{\prime}-\gamma G_{L}
\end{gathered}
$$

Where and (implicitly) are the income elasticities of capital $(K)$ and labour $(L)$, respectively, while takes the slack for $\alpha+\beta+\gamma=1$. This means that if $\gamma=0$, then the economy would be under of constant return to scale (CRS). In turn, if $\gamma<1$, then the economy would be under increasing return to scale (IRS), and if $\gamma>1$, then the economy would be under decreasing returns to scale (DRS). So if we equalize (5) and (6) and solve for $G_{T F P}$, after manipulating we obtain:

$$
G_{T F P}=G_{Y / K}^{\prime}+\beta G_{K / L}^{\prime}+\gamma\left(G_{K / L}^{\prime}+G_{L}\right)
$$

Where the term $G^{\prime}{ }_{K / L}+G_{L}$ ) is about $G_{K}^{\prime}$ ) when the yearly $G_{L}$ is small, which is normally the case. So given that $G_{K}{ }_{K}$ has been positive and relatively large over our target period, then if the economy exhibit increasing returns to scale, i.e. $\gamma<0$, assuming an unchanged $\beta, G_{T F P}$ will be smaller than under constant returns to scale (CRS). So unless the economy exhibits decreasing returns to scale, which is highly unlikely, this means that TFP under CRS should be considered as an upper limit, ceteris paribus. In the table below we assume CRS (i.e. $\gamma=0$ ) under the above considerations. We first assume $\alpha=0.5$, which seems to be the standard approach in Chile (Beltran 2017, Fuentes et al., 2006; Dipres; CNP). That is, they use some calculation of the share of capital income in $G D P$ in lieu of the elasticity $\alpha$, which as indicated above may be unwarranted on the grounds that this implicitly assumes perfect competition, and explicitly assumes a constant elasticity over the whole period. In addition, CRS might not be an appropriate assumption in all periods. The latter means that under IRS the values for TPF below are bound to be smaller, as capital and labour are assumed to have enhanced themselves endogenously, being pulled by productive and organizational changes, reducing therefore the role of the exogenous TFP. We then produce an eclectic alternative elasticity $\alpha *$ by simply averaging the capital-share value of 0.5 with our optimal incremental elasticities from our method in the Appendix (Table A1), which generates one different elasticity for each period (last column). Below we show both results, i.e. with and $\alpha$ and $\alpha *$. 
Table 3. Contributions to TFP Growth in percentage points under CRS(4)

\begin{tabular}{|c|c|c|c|c|c|c|c|}
\hline \multicolumn{4}{|c|}{$\alpha=0.5, \beta=0.5$} & \multicolumn{3}{|c|}{$\beta=1-\alpha *$} & \multirow[t]{2}{*}{$\alpha *$} \\
\hline Period & $G_{Y / K}^{\prime}$ & $\beta G_{K / L}^{\prime}$ & $G_{T P F}^{\prime}$ & $G_{Y / K}^{\prime}$ & $\beta G^{\prime}{ }_{K / L}$ & $G_{T P F}^{\prime}$ & \\
\hline 1996-2000 & -0.8 & 2.0 & 1.2 & -0.8 & 1.4 & 0.6 & 0.65 \\
\hline 2001-2005 & 0.3 & 0.9 & 1.1 & 0.3 & 1.4 & 0.3 & 0.82 \\
\hline 2006-2010 & -1.1 & 1.1 & -0.1 & -1.1 & 0.8 & -0.3 & 0.62 \\
\hline 2011-2015 & -1.1 & 1.3 & 0.2 & -1.1 & 0.9 & -0.3 & 0.67 \\
\hline Average 1991-2005 & -0.2 & 1.4 & 1.2 & -0.2 & 1.4 & 0.5 & 0.74 \\
\hline Average 2006-2015 & -1.1 & 1.2 & 0.0 & -1.1 & 0.8 & -0.3 & 0.64 \\
\hline Average 1996-2015 & -0.7 & 1.3 & 0.6 & -0.7 & 1.1 & 0.1 & 0.69 \\
\hline Y/K: capital productivity & \multicolumn{7}{|c|}{$\alpha$ : capital elasticity to income } \\
\hline $\mathrm{K} / \mathrm{L}$ : capital intensity & \multicolumn{7}{|c|}{$\beta$ : labour elasticity to income } \\
\hline TPF: total factor productivity & \multicolumn{7}{|c|}{ G': discrete growth rate (corrected for interactive terms) } \\
\hline
\end{tabular}

$\alpha^{*}$ : average $\left(0.5, \mathrm{Op} \varepsilon_{\mathrm{Y}-\mathrm{K}}\right)$

Table 3 shows the value of the growth rate of TFP $\left(G_{T F P}\right)$, decomposed into the growth rates of capital productivity $\left(G_{Y / K}^{\prime}\right)$ and that of a fraction of capital intensity $\left(G_{K / L}^{\prime}\right)$. This decomposition, which we propose, shows that TFP growth (positive or negative) has mostly relied upon positive values for capital intensity, rather than capital productivity. Notice also that now $G_{T F P}$ can be calculated directly rather than as a residual, which also means that is not quite the "coefficient of our ignorance", as it depends on known and quantifiable variables. What is behind such variables is however something more trying, just as what is behind of any macroeconomic variable, as we clarify below.

Recall that TFP theoretically represents anything that cannot be attributed to the growth of physical capital and labour of the same proportional productive quality or capacity ${ }^{(5)}$. So we call TFP any effect on income that goes beyond such a proportion. This then means that the growth of capital productivity above represents the rate of change in the embodied quality of physical capital and the disembodied architecture and organization to deploy it (including scale economies, technical efficiency, socio-political conditions, etc), while the growth of capital intensity represents changes in human capital (education, training, nutrition, health, motivation, working milieu, etc) and their socio-economic conditions and adaptations to work efficiently with both more capital and new technology. Both contributions are interrelated, but changes in capital levels and technology, whether motivated by competition, catching up, sectoral shifts, learning by doing and so on, are likely to drag and pull a good deal of the way labour is enhanced and deployed ${ }^{(6)}$. If this is so, then a good deal of fast capital accumulation represents actually important social and economic qualitative changes, which are encapsulated under the heading of total factor productivity and/or increasing returns to scale.

Under the above assumptions for $\alpha^{*}$, in terms of averages since 1996, the growth rate of TFP has contributed to the growth of GDP per worker only $0.1 \%$ a year. This being positive, but low, in the first two periods, while negative in the last two periods. This is around the results in terms of $T P F$ growth average and trend from other studies, which vary significantly between authors and studies, as shown in note 4 . The explanations for it are controversial, but there appears to be some acceptance that the significant slowdown after 1995 coincided, first, with the Asian crisis and the abandonment of countercyclical policies; second, with the World Recession and the necessary ensuing adjustments; and third, with the unavoidable upset brought by long-delayed economic reforms that started at the beginning of 2015 (Ffrench-Davis, 2018). And all along there were pretty unstable, small and negative GFCF growth rates, especially towards the end of our period (Banco Central).

It is apparent from the data that despite the assumption of a constant elasticity of capital, the TFP contribution to the growth rate of $G D P$ has been variable over time. It is however likely that the elasticity of capital has been moving together with their productivity, following the optimal incremental elasticity of it (see Appendix). But it may also be the case that overall capital elasticity was higher than 0.5 on account of likely increasing returns to scale (IRS), especially in the period of strong positive reforms, which came together with the restoration of democracy after 17 years of dictatorship (i.e. 1991-1997). If IRS is considered, this would have likely produced some significant differences for the TFP contribution to the growth rates, making it smaller over such a period. This simply means that focusing on TFP, while ignoring the possibility of IRS and the level and variability of elasticities, is likely to be misleading, especially for comparisons over time, let alone across countries.

\section{Conclusion}

We started by decomposing the actual growth rate of GDP per capita into the growth rates of capital 
productivity, capital intensity and labour participation. It shows that the most important positive contributor has been capital intensity, which for the whole period represents around $70 \%$ of the per-capita GDP growth rate, compensating for the negative contribution from the growth rate of capital productivity. In turn, labour participation has been contributing some $30 \%$ of the growth rate of GDP per capita.

We then propose a decomposition of total factor productivity (TFP) by combining an accounting decomposition with a standard production function growth accounting. The result is that the contribution to TFP growth can be separated into the growth of capital productivity and a fraction of the growth of capital intensity. Assuming CRS and using a combination of the standard elasticities used by other authors and our incremental optimal elasticities (see Appendix), we showed that the growth of TFP has been unstable and relatively poor or negative. Over the whole period, on average, TPF growth has no contribution to GDP per-capita growth rate. That is, despite that capital intensity has positively contributed to the TFP growth rate, the capital productivity growth rate has negatively contributed to it, undoing the former. In our example, $31 \%$ of the growth rate of capital intensity is actually contributing to TFP growth, which has been compensating for the negative contribution of capital productivity to it. The aim here was also to show that it seems unlikely that the marginal capital elasticity is actually constant over time, and also that capital elasticities may be larger than the ones normally used in production function studies in Chile.

Finally, recall that $T F P$, theoretically, represents anything that cannot be attributed to the growth of physical capital and labour of the same proportional productive quality and conditions. The growth of capital productivity represents the rate of change in the quality of physical capital and its production environment, while the growth of capital intensity represents changes in human capital and its socio- economic conditions and adaptations to work efficiently with both more capital and new technology, these two growth factors acting in strong interrelation. So qualitative changes especially associated with the latter seem to have been important, despite the negative TFP growth contribution from the former.

\section{Notes}

(1) We proposed and applied this method, which we termed OCM (optimal consistent method), to OECD and Latin American countries, showing comforting levels of accuracy between our capital stock series and those coming from other studies and official sources (e.g. Hofman 2000; OECD 2001), despite the use of significantly less data (see Albala-Bertrand, 2010). In addition, Hao $(2006,2004)$ compared results from the OCM for China and other existing capital series for China showing similar levels of accuracy. In contrast to other methods, the OCM takes account of measures of the productivity of capital and output at optimal levels, which are integrated into the estimation method itself. This in addition contributes to dampen productivity fluctuations due to actual capital use or idleness, which may improve the estimate of a capital stock benchmark (see Appendix).

(2) That is, the basic data on GDP, GFCF, and price indices/deflators, comes from the Central Bank of Chile; data on population, labour force, employment, wages comes from the National Institute of Statistics of Chile; while regular studies about productivity come from the Budget Directorate (Dipres) of the Ministry of Finance, and capital stock series and depreciation from particular studies carried by staff of such institutions (Fernandez \& Pinto 2017). All monetary data has been made constant to 2008 prices, unless otherwise indicated and all series are smoothened into 3-year moving averages to prevent the undue influence of rogue years.

(3) When using the logarithm transformation to produce continuous growth rates, the interactive terms are lost, which may produce some statistically significant differences from actual data, especially over the longer term, and even more if the growth rates are large. So we simply stick to discrete first differences.

(4) Of course, the estimation of TFP is a cottage industry, so other authors produce elasticities significantly different from the ones used here, showing a large variability between them. For a comprehensive reporting on them, see Beltran (2017). Among such sources, every year, the Ministry of Finance via Dipres (Budget Directorate) produces a set of given aggregate statistics that include TFP. They ask a number of known economists (between 15 and 19) to produce a forecast for the next 6 years, starting with the year in question. By the time of the reports, the latter is already in August, so it is meant to be rather accurate for this year. The results for the TFP contribution to GDP growth rates for this year, let alone the forecast ones, have wide varieties, to the point that the two extreme values are removed. For example, for 2009 the TFP range is -0.9 to -3.91 , for 2012 is -0.72 to 1.50 , for 2015 is -1.6 to 0.7 , and so on. At the beginning of the report the economists are mentioned with a number and their full names. In the stats reporting, however, you have only the number and the estimation associated to that number with a clear footnote that warns the reader that the number here does not correspond to the number associated to the economist name. In other words, the 
participants are so fully aware of the inaccuracy of results that prefer to keep their names confidential. But also it is a more honest exercise, as it avoids both collusion and public pressure, if not mockery. Our paper results fall well within the said variability. But the point is to show a TFP decomposition and in passing the possible difference between using CRS and IRS, whatever the initial levels of elasticities. The use of only two factors is sometimes called multifactor productivity (MFP), rather than total factor productivity (TFP). But as all the referred sources call it "TFP", we stick to it in this paper.

(5) That is to say that given a constant elasticity of capital (or labour), any additional percent increase in the factor, will produce exactly the same proportional effect on income as any previous percent increase of that factor, decreasing returns notwithstanding. Physical capital growth, via investment, is counted at the cost of production or its market value, and that of labour in employment levels, whether in number of hours or that of individuals. This has little to do with the productivity of capital or labour, which is then, in growth terms, encapsulated in a fixed elasticity over time.

(6) This is what is sometimes called technological change, i.e. a societal concept, as distinct from technical change, i.e. mostly an engineering concept. So it is rather misleading to claim that persisting high GDP growth rates in some countries (e.g. China, South Korea, etc.) are mostly due to brute quantities, rather than qualitative changes (i.e. the "perspiration" vs "inspiration" tagging). The other normal claim is that as soon as these gains are fulfilled, this type of TFP is exhausted. But this ignores that, on the one hand, this type of TFP sets a high platform for endogenous innovation and, on the other, even if that was not the case, countries can lock to the TFP of developed countries via imports of technology and know-how, a pattern associated with globalization. A mixed of these two is of course more likely.

(7) Linear programming is an empirical technique that optimizes an objective function via its defining parameters, subject to given inequality constraints, by means of the Simplex method (Hess, 2002). For the optimization, we use the GAMS (General Algebraic Modelling System) software. We estimate our optimal parameters over 5-year periods, so we assume them constant at optimal level, over such periods. The constancy of capital-output ratios, especially at optimal levels, is a reasonable assumption, which can come about either via correcting capital series by removing idle capital (which is hardly straightforward) or by optimizing the productive capacity of uncorrected series of capital or investment over the target periods, as we have done here (Albala- Bertrand 2010). We also assume that capital is the dominant factor of production, in the sense that it drags or pulls the other factors in the economy. This is standard assumption, explicitly or not, in many growth models and empirical models, e.g. Harrod- Domar model or the AK endogenous model, among others (Thirlwall, 2011; Taylor, 2004; Aghion \& Howitt, 1998; Blades, 1993; Jones, 1975), which should be acceptable, especially when focusing in shorter periods, and also when labour availability does not seem to be a constraint, as in Chile over our target period.

(8) We also averaged the depreciation rates estimated by the Central Bank of Chile over our 5-year periods, so implicitly we assume the same depreciation over it.

(9) The incremental income elasticity of capital can be defined as $\varepsilon_{\mathrm{Y}-\mathrm{K}}=(\Delta Y / \Delta K) /(Y / K)$. Then $\Delta Y / \Delta K$ comes from our 5-year incremental optimal capital productivity $(\mathrm{Op} \Delta Y / \Delta K)$, while for $(Y / K)$ we used the optimal $\mathrm{Y}$ from the OCM and the estimated K series from Fernandez \& Pinto (2017), all in 5-year averages. This should give us an optimal elasticity, as this $\mathrm{K}$ series contains the total estimated capital without discounting for idleness. So it is a more accurate measure of average capital productivity than using the actual income, as the latter is likely to underestimate such productivity, i.e. actual income, as a rule, is bound to be on average lower than the optimal one, so its productivity will also be lower by using the same estimated capital levels.

\section{References}

Aghion, P., \& Howitt, P. (1998). Endogenous Growth Theory.Cambridge, Mass.: MIT Press.

Albala-Bertrand, J. M. (2010). A Contribution to Estimate a Benchmark Capital Stock. An Optimal Consistency Method. International Review of Applied Economics, 24(6), 633-647. https://doi.org/10.1080/02692171.2010.512128

Albala-Bertrand, J. M., \& Hao, F. (2007). Net Capital Stock and Capital Productivity for China and Regions: 1960-2005. An Optimal Consistency Method. Queen Mary, University of London, Department of Economics Working Paper No. 610. http://www.econ.qmul.ac.uk/research/workingpapers/2018/

Banco Central (2016). Cuadro Económico Integrado 2003-2015. Chile: Banco Central. https://si3.bcentral.cl/estadisticas/Principal1/informes/anuarioCCNN/index_anuario_CCNN_2016.html

Banco Central (various years). Cuentas Nacionales. Chile: Banco Central. 
http://www.bcentral.cl/web/guest/cuentas-nacionales-anuales

Beltrán Bravo, F. (2017). Productividad Total de Factores: Una Estimación Estructural y sus Determinantes en Chile durante el Período 1960-2015. MSc Thesis for Economía y Negocios, University of Chile. http://repositorio.uchile.cl/handle/2250/144305?show=full

Blades, D. (1993). Comparing Capital Stocks. In Adam Szirmai, Bart van Ark and Dirk Pilat (Eds.), Explaining Economic Growth - Essays in Honour of Angus Maddison (pp. 399-409). Amsterdam: North-Holland.

Casen (various years). Encuesta de Pobreza y Desigualdad. Chile: Ministerio de Desarrollo Social. http://observatorio.ministeriodesarrollosocial.gob.cl/casenmultidimensional/casen/casen_2015.php

CNP (Comisión Nacional de Productividad) (various years) - Nota Medición de Productividad. Chile. http://www.comisiondeproductividad.cl/estudios-finalizados-2/

Denison, E. F. (1993). The Growth Accounting Tradition and the Proximate Sources of Growth. In Adam Szirmai, Bart van Ark and Dirk Pilat (Eds.), Explaining Economic Growth - Essays in Honour of Angus Maddison (pp.37-45). Amsterdam: North- Holland.

Dipres (various years). Comité consultivo del PIB tendencial (Budget Directorate). Chile: Ministerio Hacienda. http://www.dipres.gob.cl/598/w3-propertyvalue-16157.html

Fernández, I., \& Pinto, P. (2017). Medición de los Servicios de Capital para la Economía Chilena. Estudios Económicos Estadísticos, Chile: Banco Central. http://www.bcentral.cl/web/guest/estudios-economicos-estadisticos

Ffrench-Davis, R. (2014). Chile entre el Neoliberalismo y el Crecimiento con Equidad: Reformas y Políticas Económicas desde 1973 (5ta Edición). Chile, Santiago: J.C. Sáez.

Ffrench-Davis, R. (2018). Reformas económicas en Chile 1973-2017. Chile, Santiago: Penguin Random House Grupo Editorial.

Fuentes, R., Larraín, M., \& Schmidt-Hebbel, K. (2006). Sources of Growth and Behavior of TFP in Chile. Cuadernos de Economía (Pontificia Universidad Católica de Chile), 43, 113-142.

Hao F. (2006). Estimate of Provincial Capital Stock in China: 1952-2004. Journal of Data Analysis (Taiwan), l(6), 6-13.

Hao, F. (2004). Research about Our Country's Capital Stock. Unpublished dissertation Submitted to TUFE.

Hess, P. (2002). Using Mathematics in Economics Analysis. New Jersey: Prentice Hall.

Hofman, A. (2000). The Economic Development of Latin America in the Twentieth Century. Cheltenham: Edward Elgar.

Hulten, C. R. (1992). Growth Accounting When Technical Change is Embodied Capital. American Economic Review, 82(4), 565-582. https://doi.org/10.3386/w3971

Jones, H. (1975). An Introduction to Modern Theories of Growth. Middlesex: Thomas Nelson \& Sons.

OECD (2001). Measuring Capital (OECD Manual), Paris: OECD. http://www.oecd.org/sdd/productivity-stats/43734711.pdf

OECD (various years). Income Inequality. https://data.oecd.org/inequality/income-inequality.htm.

Peach, E. K., \& Stanley, T. D. (2009). Efficiency Wages, Productivity and Simultaneity: A Meta-Regression Analysis. Journal of Labour Research, 30(3), 262-268. https://doi.org/10.1007/s12122-009-9066-5

Taylor, L. (2004). Reconstructing Macroeconomics. Structuralist Proposals and Critiques of the Mainstream. London: Harvard University Press.

Thirlwall, A. P. (2011). Economics of Development (9th ed), New York: Palgrave Macmillan. https://doi.org/10.1007/978-0-230-34440-2 


\section{Appendix: Estimation of the Optimal Incremental Indicators}

Below we estimate the optimal incremental capital productivity and the optimal incremental income elasticity to capital by means of a linear programming approach. Following a variation of our proposed method to calculate a reasonable benchmark capital stock with little data availability (see Albala-Bertrand 2010), for each year, output $(Y)$ is defined as $Y_{t}=Y_{t-1}+\Delta Y$, which is a definition of a first difference. From here, we apply a simple functional mechanism via the productivity of capital to the two right-hand side terms, so that $Y t-1=\delta b K t-2 \mu$ and $\Delta Y=\delta_{a} I t-1$, where $\delta_{b}$ and $\delta_{a}$ are respectively the average and incremental capital productivities, while $\mu=(I-\lambda)$ is the depreciation rate, $K$ is the capital stock, $I$ is investment, and " $t$ " is any given year. The depreciation rates used are the 5-year averages that come from the capital stock estimation carried by Fernandez \& Pinto (2017). This functional form assumes that labour, required row materials and other productive requirements are available, which may not be too strong assumptions for Chile. These requirements, by the way, are almost always assumed as available in production function studies, whether that is the case or not.

We also assume the standard convention that new capital becomes productive with one year lag. Optimal output is then defined as $Y^{*} t=\delta_{b} K_{t-2} \mu+\delta_{a} I_{t-1}$. Where $\delta_{b}=Y^{*} / K$ and $\delta_{a}=\Delta Y^{*} / \Delta K$ are respectively the average and incremental capital productivities, corresponding to that optimal output, and the symbol "*" denotes "optimal". Let $K t-2=K b y$ be the base-year capital stock. Then the iterative solution of the above equation for any one year " $t$ " is:

$$
Y_{t}^{*}=\delta_{b} K_{b y} \mu^{t}+\delta_{a} \sum_{i=1}^{t} I_{i-1} \mu^{(t-i)}
$$

Where the year " $t$ " ranges from 1 to $n$. The base year $K b y$ would correspond to the year before the 5-year periods for gross capital formation $(G F C F)$ and $G D P$, which we use to estimate the said parameters (e.g. 1995 when the GFCF series start in 1996). The initial or base-year product $\delta_{b} K b y$ and the incremental productivity coefficient $\delta_{a}$ are the two parameters that our estimation approach will throw. But in this paper we are only interested in the latter, as this would correspond to the incremental productivity of capital, i.e. the productivity of the accumulated investment over our 5-year periods. We will also use $Y_{t}^{*}$ to estimate the optimal incremental income elasticity to capital, as explained later. We then estimate the said parameters by means of a standard linear programming (LP) ${ }^{(7)}$, which takes the following form (Ibid.):

Minimize:

$$
Z=\sum_{t=1}^{n}\left(Y_{t}^{*}-Y_{t}\right)=\left(\delta_{b} K_{b y} \sum_{t=1}^{n} \mu^{t}+\delta \sum_{a}^{n} \sum_{t=1}^{t} I_{i=1} \mu^{(t-i)}\right)-\left(\sum_{t=1}^{n} Y_{t}\right)
$$

Subject to: $Y_{t}^{*} \geq Y_{t}, \delta_{b} K_{b y}$ and $\delta_{a} \geq 0$

Where $\mathrm{n}=5$ corresponds to the length of our series (e.g. when 1996 is the initial year for GDP and GFCF, then 2000 would be the last year, and the base-year capital stock would then be 1995). We estimate such parameters from a moving 5-year period from 1996 to 2015. This then generates our target parameter a, i.e. the optimal incremental capital productivity, over such period. This is then averaged in 5-year periods from 1996 to 2015.

We apply the above methodology, using the data for investment $(G F C F)$ and output $(G D P)$ that comes from official statistics. To prevent a single rogue year from having undue influence on the optimal point, we apply a three-year moving average to both series over the sample period. Finally, all series have been made constant to 2008 prices via available deflators ${ }^{(8)}$. 
Table A1. Optimal Levels of Incremental K-Productivity, Average K-Productivity and Income Elasticity to Capital

\begin{tabular}{cccc} 
Period & Op $\boldsymbol{\Delta} \boldsymbol{Y} / \boldsymbol{\Delta} \boldsymbol{K}$ & Op $\boldsymbol{Y} / \boldsymbol{K}$ & Op $\boldsymbol{E}_{\boldsymbol{Y}-\boldsymbol{K}}$ \\
\hline $\mathbf{1 9 9 6 - 2 0 0 0}$ & 0.35 & 0.43 & 0.8 \\
$\mathbf{2 0 0 1 - 2 0 0 5}$ & 0.47 & 0.41 & 1.1 \\
$\mathbf{2 0 0 6 - 2 0 1 0}$ & 0.30 & 0.41 & 0.7 \\
$\mathbf{2 0 1 1 - 2 0 1 5}$ & 0.32 & 0.39 & 0.8 \\
Average 1996-2005 & 0.41 & 0.42 & 0.98 \\
Average 2006-2015 & 0.31 & 0.40 & 0.78 \\
Average 1996-2015 & 0.36 & 0.41 & 0.88 \\
\hline Op $\Delta Y / \Delta K:$ optimal incremental K-productivity & & \\
Op $Y / K:$ optimal average K-productivity & & \\
Op $\varepsilon_{Y-K}:$ optimal income elasticity to K
\end{tabular}

Table A1 shows the optimal incremental and average capital productivities, and the optimal income-to-capital elasticity ${ }^{(9)}$ from 1996 to 2015, split in 5-year periods. It shows that incremental capital productivity has fallen towards 2015, after an increase in 2001-2005. This also shows that the average capital elasticity over the whole period is around 0.9, with a larger average over 1996-2005 of around 1.0, decreasing to around 0.8 towards 2006-2015. The importance of this is simply that (i) it seems unlikely that the actual economy, as distinct from a theoretical production function, exhibits a blanket constant marginal capital elasticity, (ii) the marginal capital productivity may be larger than the ones normally used, and/or (iii) constant returns to scale may be too strong an assumption. The standard approach is first to assume constant returns to scale, but increasing returns may also be an acceptable proposition, especially when developing countries grow fast in some periods; second, to assume that capital elasticity can be replaced with the capital share in total income, so implicitly assuming perfect competition, which may be highly unlikely; and lastly the use a of a blanket constant elasticity over the whole period, which may be unwarranted.

\section{Copyrights}

Copyright for this article is retained by the author(s), with first publication rights granted to the journal.

This is an open-access article distributed under the terms and conditions of the Creative Commons Attribution license (http://creativecommons.org/licenses/by/4.0/). 